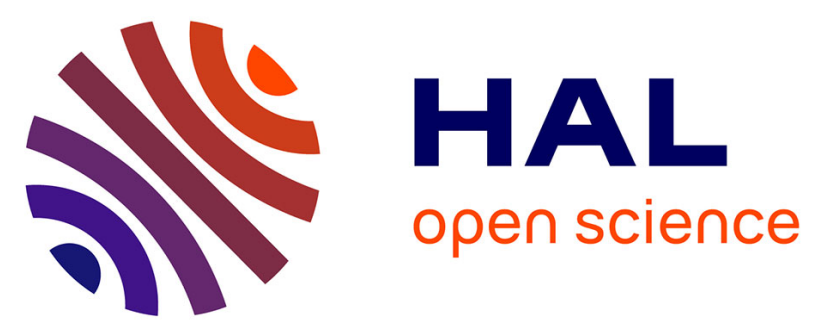

\title{
A Proposal of Value Co-creative Production with IoT-Based Thinking Factory Concept for Tailor-Made Rubber Products
}

Toshiya Kaihara, Daisuke Kokuryo, Swee Kuik

\section{- To cite this version:}

Toshiya Kaihara, Daisuke Kokuryo, Swee Kuik. A Proposal of Value Co-creative Production with IoT-Based Thinking Factory Concept for Tailor-Made Rubber Products. IFIP International Conference on Advances in Production Management Systems (APMS), Sep 2015, Tokyo, Japan. pp.67-73, 10.1007/978-3-319-22759-7_8. hal-01431157

\section{HAL Id: hal-01431157 \\ https://hal.inria.fr/hal-01431157}

Submitted on 10 Jan 2017

HAL is a multi-disciplinary open access archive for the deposit and dissemination of scientific research documents, whether they are published or not. The documents may come from teaching and research institutions in France or abroad, or from public or private research centers.
L'archive ouverte pluridisciplinaire HAL, est destinée au dépôt et à la diffusion de documents scientifiques de niveau recherche, publiés ou non, émanant des établissements d'enseignement et de recherche français ou étrangers, des laboratoires publics ou privés.

\section{(c)(1)}

Distributed under a Creative Commons Attribution| 4.0 International License 


\title{
A Proposal of Value Co-Creative Production with IoT-based Thinking Factory Concept for Tailor-made Rubber Products
}

\author{
Toshiya Kaihara, Daisuke Kokuryo and Swee Kuik \\ Kobe University, Graduate School of System Informatics, \\ 1-1, Rokkkodai, Nada, Kobe 657-8501, Japan \\ kaihara@kobe-u.ac.jp
}

\begin{abstract}
Production companies are required to notice the importance of the paradigm shift from "use value" into "value in use" about their products and services. Value co-creative activity between the producers and consumers is essential to realise the paradigm shift in practical business case. The IoT(Internet of Things) is a powerful infrastructure to digitalise and increase the integration of vertical and horizontal value chains in the business process. We propose a value co-creative production system model under IoT environment with an innovative "Thinking factory" concept. Our current target is the rubber industry which is required to provide tailor-made products as human-machine delicate interface.
\end{abstract}

Keywords: Value co-creation, Smart factory, IoT, CPS, Multiagent system

\section{Introduction}

Nowadays production companies are required to pay attention into the importance of the paradigm shift from "use value" into "value in use" about their products and services. Value co-creative activity between the producers and consumers is essential to realise the paradigm shift in practical business case. The IoT(Internet of Things) is a powerful infrastructure to digitalise and increase the integration of vertical and horizontal value chains in the business process. Therefore smart production concept is now paid great attention in accordance with the development of ICT. Industry 4.0 in Germany [1] and Industrial Internet Consortium (IIC) initiative in USA [2] are the most famous projects focusing on the smart factory. IoT (Internet of Things) and CPS (Cyber Physical System) are their key technologies to support the realization of Smart factory.

On the other hand, Kobe area is the birthplace of the rubber industry in Japan and the country's largest base of chemical shoes. It is utmost important for Kobe area to realize an innovative outcome of the rubber industry under the global competition. This innovation is expected to enhance the competence of Japanese manufacturing technology. We focus on the shoe industry with rubber materials as consumer products, because it is one of very important production businesses in Kobe area as mentioned before. 
Currently because of current modern life and life longevity, it has become common to put on shoes daily for long time. Shoes have become very important to support the total body weight of its own. Consumers pay much concern to "foot comfort" or "shoes fit feeling" in various life scenes, such as health promotion, rehabilitation, running or other sports, business use, and so on. Thus the shoes industry is one of the most suitable target to try to implement the value in use concept with the idea of tailor-made rubber products.

In this paper we introduce our research activity as a part of the "Innovative Design and Production Technology Project" under the cross-ministerial SIP (Strategic Innovation Promotion) program [3] supported by Cabinet Office, Government of Japan [4]. We propose design/manufacturing systems targeting value-co-creation for our life innovation focusing shoes as pioneer model in the rubber industry as well as realising tailor-made rubber products with reactive $3 \mathrm{D}$ printer in our R\&D activity.

\section{Thinking factory concept under IoT}

As we mentioned before, smart production concept is now paid great attention as IoT environment is spreding. Industry 4.0 and IIC are the most famous projects focusing on the smart factory. The technological map between Industry 4.0 and IIC is illustrated in figure 1.

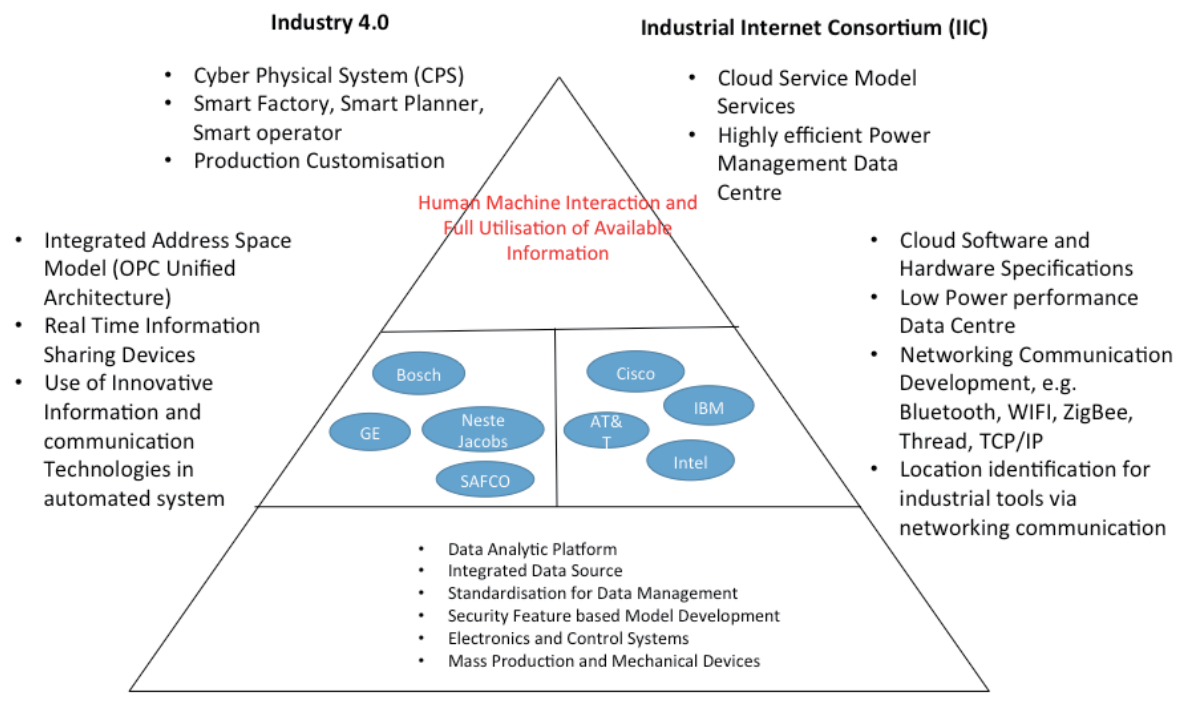

Fig. 1. Industry 4.0 and IIC

Industry 4.0 is based on CPS and IoT, and tries to facilitate the smart factory in terms of automation and integration amongst supply chain. On the other hand 
IIC is more based on Cloud computing and tries to enable stakeholders in the manufacturing industry to form collaborative $\mathrm{R} \& \mathrm{D}$ via IoT.

Industry 4.0 was first introduced by the German Government in order to increase visibility of the operational activities in the factory by use of advanced manufacturing technologies and promote decentralisation management [5]. The key focus is on the development of cyber physical system (CPS) [6]. CPS is defined as the advanced manufacturing technologies for controlling and handling inter-operative systems, where physical assets is associated with computational capabilities and elements. In this context, Lee et al. provides the 5C architecture guideline for Industry 4.0 in which the data sources are based on sensor, controller and networked systems. This proposed architecture includes the smart connection level, data-to-information conversion level, cyber level, cognition level and configuration level [7].

The Industrial Internet Consortium (IIC) was established in March 2014 by an alliance of technology development companies [2]. These partnership companies include AT\&T, Cisco, GE and Intel. They are currently working on the focused areas of improvement in software and hardware platforms towards excellent networking by identifying and implement best practices using IoT. Currently, these partnership companies attempt to incorporate new strategy by rectifying the current system weaknesses to ease of implementation by IoT. In addition, the development on networking connectivity via cloud computing is one of the key focuses for the IIC for improving and standardising the core activities for implementation guideline using IoT shown in figure1.

Our thinking factory concept for realizing the value co-creative production is shown in figure 2. Several kinds of users are interactively connected with thinking factory under IoT environment. Our concept also contains CPS, cloud computing and big data analysis, and it focus more on uses value creation as well as producers value.

For sustainable value creation, our thinking factory mutually circulates both traditional producer innovation providing values and user innovation providing values created by users' participation. Involvement of users in design and development evolves wide spectrum of technologies realizing potential needs. Proposal by researchers of new product or service will inspire idea creation of future product or service.

Value co-creatiive production between value producer and value consumer could be established by our thinking factory concept under IoT environment as illustrated in figure 3. Value market is constructed in the "Value in use" production, and the development about both product and customer is carried out under the mechanism.

CPS is a decentralization concept through the intelligent system to arrive at smart production. Several developed technologies for managing computational element between its physical assets and computational capabilities enables CPS with cloud platform. We have already proposed "Real-Virtual fusion manufacturing system" concept [8] which includes CPS characteristics in dynamic pro- 


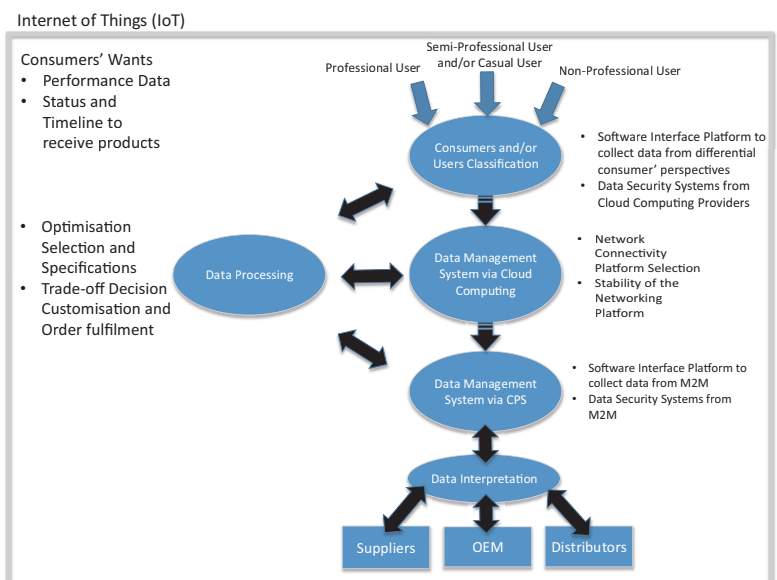

Fig. 2. Thinking factory concept with customers involvement

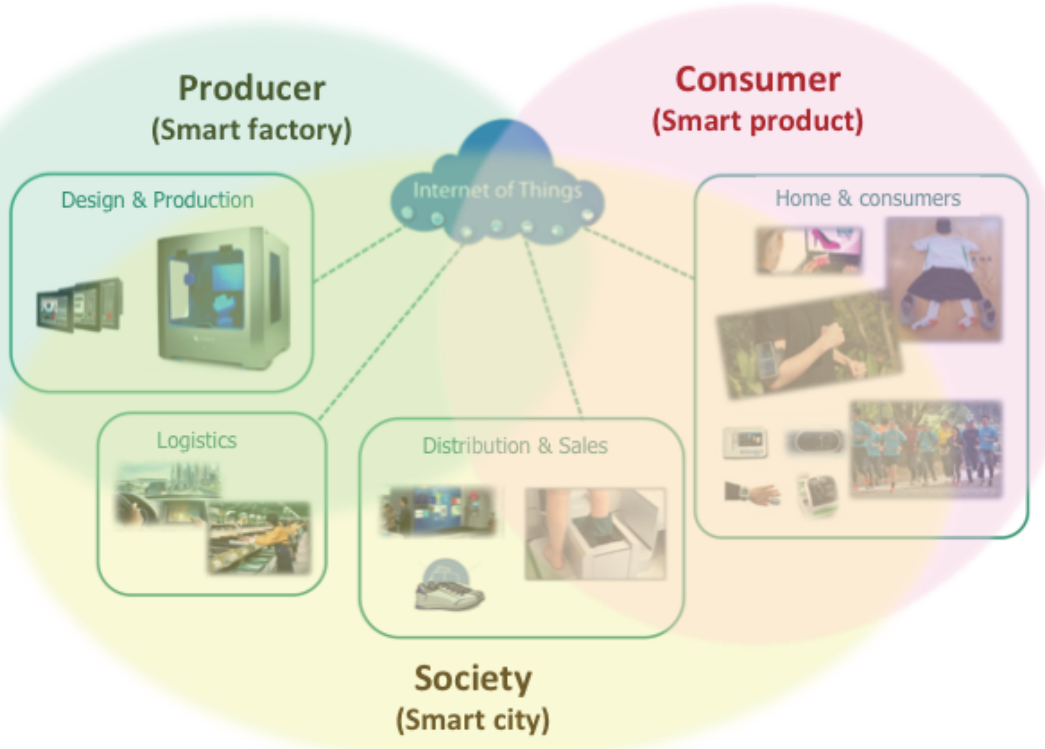

Fig. 3. Value co-creative production under IoT 
duction management, and we are now implementing it into our thinking factory model.

Several research activities are carried out in our project, and we will explain consumer-baed supply chain for tailor-made rubber products as an example in the next chapter.

\section{Consumer-based production model for tailor-made rubber products}

Total business flow in the proposed value co-creative tailor made production system for shoe industry is shown in figure 4. All of users, marketing/product design/procurement/ordering departments, production sites, and retailers are connected via IoT. All the related data are circulated, and interactive design \& production are executed amongst users, designers, and producers.

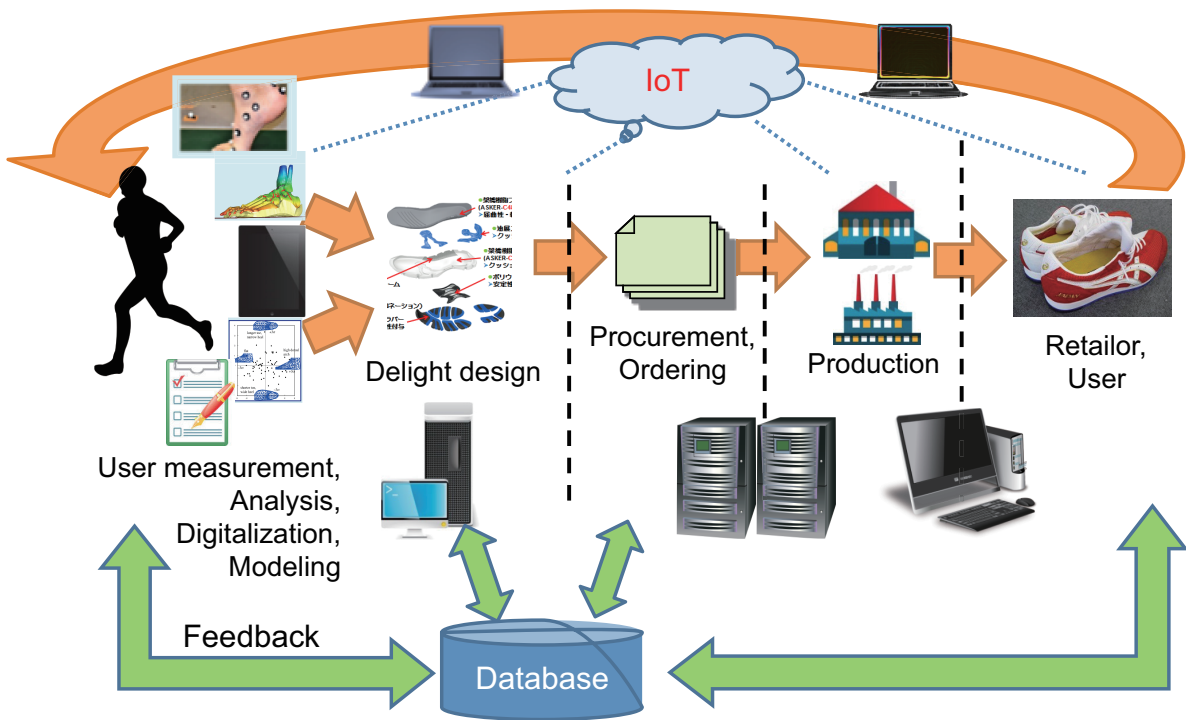

Fig. 4. Value co-creative tailor made production system

Several research activities are executing now in our project, and we will explain consumer-baed supply chain for tailor-made rubber products as an example. The consumer-based supply chain model is proposed to manage and handle the inter-relationship of supplier-manufacturer and manufacturer-distributor parties. In recent literature, the research works on production inventory policy only focus on either supplier-manufacturer inventory or manufacturer-distributor inventory policies in multiple product conditions [9],[10]. However, the interaction of all supply chain members for planning inventory policy may have direct 
impact on cost savings. As illustrated in figure 5, both parties (i.e. suppliermanufacturer and manufacturer-distributor) require to work closely in order to achieve cost minimisation for the entire supply chain network. In this modelling, the multiple distributors are responsible for different product customisations and delivery according to the requirements of the consumer segments. In fact, the inventory policy in product customisations for supplier-manufacturer and manufacturer-distributor parties can vary in terms of quantities, ordering size and differential consumer segments. These variations may then increase the operational costs along a supply chain.

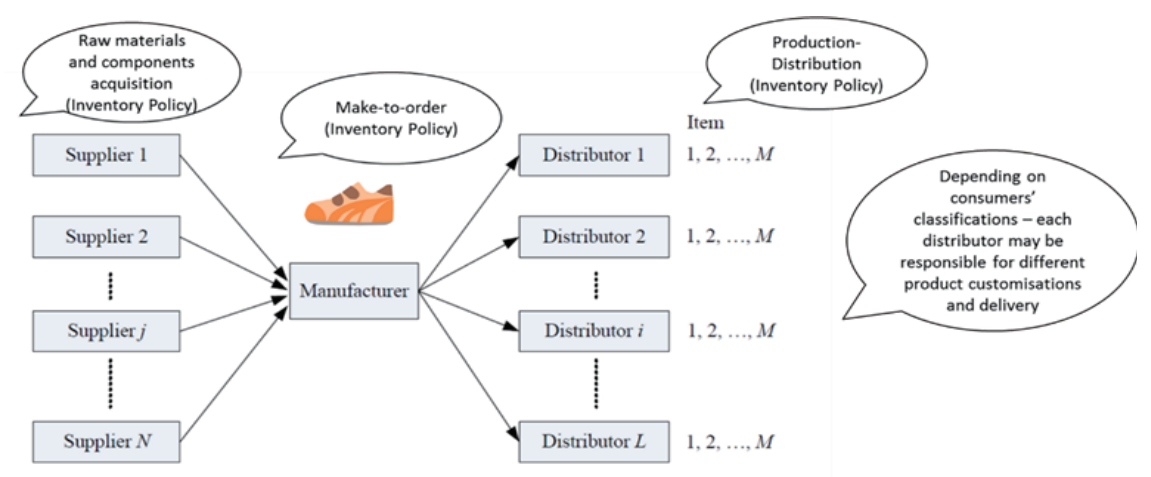

Fig. 5. Supply chain network for product customisation

In our activity the integrated production inventory policy in a supply chain is relatively complex to be planned for $3 \mathrm{D}$ printing product customisations. The policy usually needs to incorporate with the demand fluctuation, ordering size, differential consumer segments, and 3D printing machine capabilities. Figure 6 illustrates a schematic diagram of the integrated inventory policy for both parties in 3D printing product customisations. The raw materials and components used can actually move across multiple entities along a supply chain, such as supplying, producing and distributing to consumers.

The appropriate supply chain planning in inventory policy from initial acquisition, make-to-order and production-distribution is required to minimise the associated cost along its value chain. This is also known as three echelon supply chain perspective. For optimising the gained profit and added value for implementation, there is a need to develop an integrated system modelling to simulate the complexities of differential consumer requirements in 3D printing rubber product customisations.

\section{Conclusion}

We introduced our proposed concept on "value co-creative production system model" under IoT environment, which facilitates an innovative "Thinking fac- 


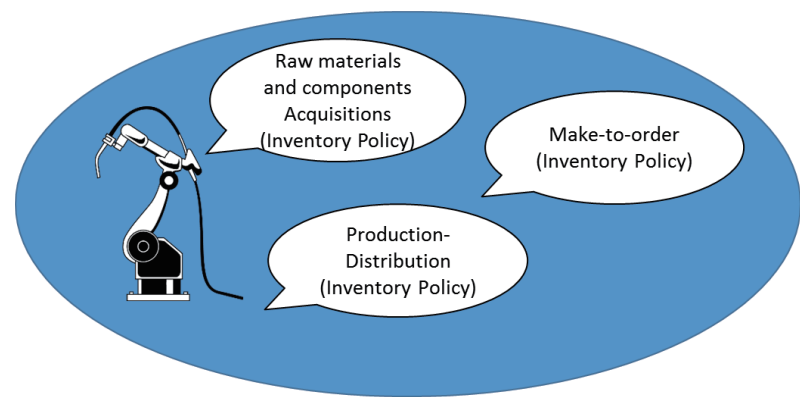

Fig. 6. Integrated inventory policy in $3 \mathrm{D}$ printing product customisation and consumer segments

tory" structure targeted to the rubber industry in Kobe area. Deep involvment of users into the IoT based production system were investigated, and that is an important difference from Industry 4.0 or IIC in the abroad. The framework of users' participation to value co-creation was constituted by Kobe University, prefectural research institute located in Kobe area, and many leading business companies as provider or user. Our activity tries to realise the innovative paradigm shift from "use value" production into "value in use" production in the near future.

\section{Ackowledgement}

Our activity is fully supported by the "Innovative Design and Production Technology Project” under the cross-ministerial SIP (Strategic Innovation Promotion) program organized by NEDO (New Energy and Industrial Technology Development Organization) and Cabinet Office, Government of Japan.

\section{References}

1. http://www.plattform-i40.de

2. http://www.iiconsortium.org

3. http://www8.cao.go.jp/cstp/gaiyo/sip/ (In Japanese)

4. http://www.cao.go.jp/index-e.html

5. Dworschak, B. , Zaiser H.: Competences for Cyber-physical Systems in Manufacturing - First Findings and Scenarios, Procedia CIRP, 25(0): p. 345-350 (2014).

6. Lee, J., Bagheri B., Kao, H.-A: A Cyber-Physical Systems architecture for Industry 4.0-based manufacturing systems, Manufacturing Letters, 3(0): p. 18-23 (2015).

7. Zuehlke, D.: SmartFactory-Towards a factory-of-things. Annual Reviews in Control, 34(1): p. 129-138 (2010).

8. Qian, Y., Fujii, N., Kahara, T., Fujii, S., Umeda, T.: Production Scheduling with Social Contract Based Approach for Real-Virtual Fusion Manufacturing System, Proc. of the 44th CIRP conference on manufacturing systems (CD-ROM): PaperID91 (2011). 
9. Hoque, M.A.: An optimal solution technique to the single-vendor multi-buyer integrated inventory supply chain by incorporating some realistic factors, European Journal of Operational Research, 215(1): p. 80-88 (2011).

10. Rad, R.H., et al.: Optimizing an integrated vendor-managed inventory system for a single-vendor two-buyer supply chain with determining weighting factor for vendor s ordering cost, International Journal of Production Economics, 153(0): p. 295-308 (2014). 